\title{
A METHOD OF ESTIMATING THE COSTS OF UNEXPECTED RUNWAY CLOSURES DUE TO ACCIDENTS AND INCIDENTS
}

\author{
Rob Van Eekeren ${ }^{1}$, Stephen Wright ${ }^{2}$, Olja Čokorilo ${ }^{3}$ \\ ${ }^{1}$ Safe-runway GmbH, Route de Nendaz, Nendaz, VS, Switzerland \\ ${ }^{2}$ Faculty of Engineering, University of Leeds, Leeds LS2 9JT, UK \\ ${ }^{3}$ University of Belgrade, Faculty of Transport and Traffic Engineering, Vojvode Stepe 305, 11000 \\ Belgrade, Serbia
}

Received 3 July 2017; accepted 22 August 2017

\begin{abstract}
Accidents occur on or near runways. These result in damage to equipment and property, extra operational costs, temporarily loss of turnover and endanger human life's. Specific mitigations to increase runway safety are taken since two decades. Specific action plans such the EAPPRE/EAPRRI do not express the mitigations and their safety benefits in costs saved. That precludes a cost effective approach to runway accident mitigations, which limits further runway safety enhancements. A cost effective method will not only be beneficial for aviation safety but also for aircraft operators and aerodrome operator's competiveness and ultimately for the passengers. For a cost effective approach is insight in the world wide costs associated with all runway events needed. This has not been done so far. Our model enables a reasonable estimate of the costs resulting from unexpected runway closures due to accidents or incidents. The model uses 18 runway accident related variables and has a transparent structure of realistic assumptions. Data are gathered from open sources. The model is flexible enough to allow updating of input data and/or assumptions when better would become available. Break down in the various components of the costs to great extends is made possible, allowing insight and also prioritizing of future mitigations. The root causes and contributing factors leading to the runway accidents are not incorporated, the model focuses on the financial impact corrected for regional purchasing power. For 2016 are the costs associated with unexpected runway closures due to accidents or incidents estimated at 4.2 Billion Dollar, whereof the costs for aircraft operators are $2.4 \mathrm{~B} \$$; aerodrome operators $0,16 \mathrm{~B} \$$; Indirect Safety Costs $1.3 \mathrm{~B} \$$ and the cost of Human injuries and fatalities 0,3 B $\$$.
\end{abstract}

Keywords: runway safety, accident costs, excursions costs, incursion costs.

\section{Introduction}

Aviation is very safe; the (EASA, 2017) annual safety overview fatal accident rate per $10 \mathrm{M}$ departures remains steady under 2 , whilst the non-fatal accident rate is stable around 20 per $10 \mathrm{M}$ departures. Meaning that safety improvements are just capable of keeping up with aviation growth.
Unexpected runway safety events could cause a temporarily closure of the runway of an aerodrome. These events include runway excursions, underruns, incursions as well as on runway events with aircraft restricting normal runway operations. Closing a runway as a result of an accident or incident results in delays, diversions, the loss of aerodrome revenues and next

${ }^{1}$ Corresponding author: robvaneekeren@safe-runway.com 
to possible damage to equipment, property and injuries also various extra costs.

Traditionally accidents are expressed in different entities, such as the number of casualties, injuries and the level of damage. How could, by example, the outcome of a fully burned A340, with 12 injuries (AF 358 CYYZ, 2005) be compared with a substantial damaged Embraer 190 with no casualties (EQ173, SECU, 2016), which closed the airport down for a week, or, be compared with an cargo Antonov 12B with 7 fatalities (Silk Airways ,OADY,2016), or with over 300 General Aviation accidents resulting in over 100 injuries and over 30 fatalities (year 2016)? Where should the priority of mitigations be? In order to avoid comparing apples with oranges, a common entity is needed to express the outcome of runway related accidents and make prioritizing and cost effective mitigations possible.

The European Action Plans on the Prevention of Runway Incursions and Runway Excursions (EAPPRE, 2013; EAPPRI, 2012) do not include financial arguments, neither take cost effective mitigations into account. Since risk is a function of likelihood and impact, both factors could reduce the risk. The European runway safety plans focus only on the reduction of the likelihood, leaving the impact mitigations outside the equation. That is half sighted and precludes an objective cost effective approach.

Individual aircraft operators, insurance companies, aerodrome operators and others may have estimates about a specific high-level accident. The specific financial consequences are however not integrated, precluding a comprehensive insight and thus restrict authorities and stakeholders. E.g. the aircraft operator of the accident aircraft may know what the level of damage to the aircraft is, but not with the costs associated with the diversions costs for other aircraft operators, the opportunity costs for the aerodrome, the costs of human injuries, etc. Insight in the costs related to the yearly worldwide runway occurrences is not available. The financial consequences from low level accidents or incidents are often not published at all. This precludes a real cost effective approach to runway safety.

Could the law of diminishing returns show its financial limits of restricting further reductions of the likelihood of runway related accidents? The "low hanging fruits", as focused on prevention are already implemented (European Prevention Action Plans). The law of diminishing returns, might pose a halt in further mitigations enhancing runway safety. That would result in more runway accidents, causing more risk to society. To overcome this is insight in the most relevant costs required.

Therefore a single entity showing the consequences to society of runway related accidents is needed. The main question is therefore if a generic worldwide reasonable cost estimation could be made available.

\subsection{Type of Accident / Incident}

Traditionally is the severity of runway incursions classified in categories (A,B,C and $D)$. Separately are runway excursions defined as veer offs or overruns. That provides however a limited insight on the factual effect to society of all runway related occurrences. A more practical and comprehensive distinction is therefore needed. The EUROCONTROL skybrary practical definitions are taken for distinction between the various types of events 
(runway incursions A,B,C,D and runway excursion: underruns, veer-offs and overruns (EUROCONTROL, 2017). "On runway occurrences" are additionally also identified. These compromise all occurrences where the accident/incident aircraft remained on the runway, however disrupted the normal flow of operation. E.g. an aircraft with a blown tire taxiing clear of the runway would not be counted, but an aircraft with a blown tire, resulting in on runway evacuation, would. This results in three different types and three subtypes of runway safety events.

- Runway Incursions (A, B, C and D);

- Runway Excursions, existing of:

- Runway Underruns;

- Runway Veer offs;

o Runway Overruns;

- On runway occurrences.

\subsection{Runway Accident Database}

\subsubsection{Sources}

The states incident / accident reporting availability is not mature enough on a global scale to allow a comprehensive analysis Various data sources (references; list of data sources) are consulted in order to derive to a reasonable complete database of runway occurrences. These include aviation authorities data as well as open source data, such as news papers, articles and websites. The main advantage of also using unofficial reports is it allows completion of what has occurred and these provide more and up-todate occurrences.

The worldwide runway safety events since January $1^{\text {st }} 2016$ have been categorized and analyzed. Not all sources use a uniform system of classifying the runway safety events; some accidents and severe incidents were not classified as e.g. a runway excursion, whilst they should have; others did not have a classification at all. This required specific analysis of what happened to allow categorizing. Each occurrence is categorized right after the accident (as far as adequate information could be gathered) occurred in order to arrive to the most likely type of runway event.

\subsubsection{Data of Runway Occurrences}

Runway related occurrences with motorized fixed wing aircraft that would likely have an effect to society are taken into account. Effect to society could vary from runways or airport closures, delays, disruption of normal flight schedules, damage to equipment or property and / or injuries and fatalities. E.g. the runway incursion incident categories (A, B, $\mathrm{C}$ or D) are by themselves alone not included; however a runway incursion with damage (e.g. the collision at 4th April at WIHH between an ATR-42 and B738) or resulting in a runway closure, will be. All incidents and accidents have individually been analysed on their potential effect on runway closures, disruption of operation, damage to equipment or property, injuries and casualties.

643 Worldwide runway safety events occurred in 2016 have been categorized, analyzed and form the basis for the runway events costs estimates. These 643 events, provide10.000 data fields with half a billionvariation possibilities. A part of the database set-up is show below as example. The database has been set-up flexible enough to allow alterations of data from a specific incident or accident when better data would become available later (e.g. by feedback or accidents reports in a later stage). Not all occurrences in the database are verified by official reports. 


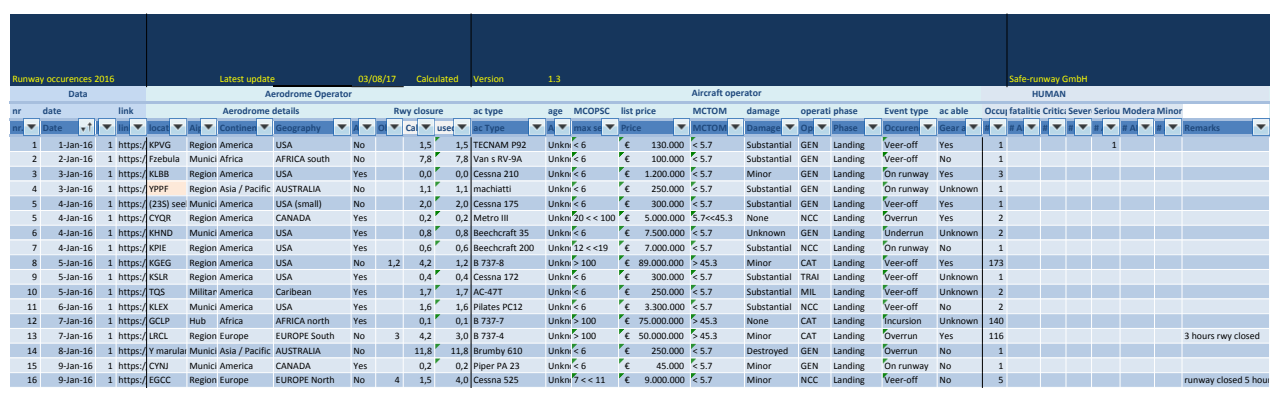

Fig. 1.

Example Database

Source: Safe-Runway GmbH

\section{Method}

A great number of factors determine the associated costs and require specific data. Not all data are directly available and needed either to be estimated or assumed.

The process to derive the runway accident related costs consist of four steps: the development of a comprehensive world wide database covering the known runway safety events with a potential effect on runway closure, develop a model capable to provide an estimate of the generic costs involved in each incident or accident and finally analyse and categorise these cost. The model is flexible enough to incorporate new data on occurred events when they would become available.

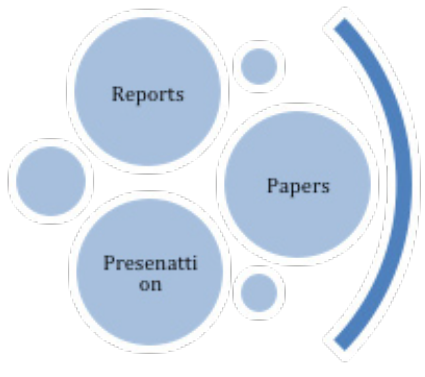

Literature research

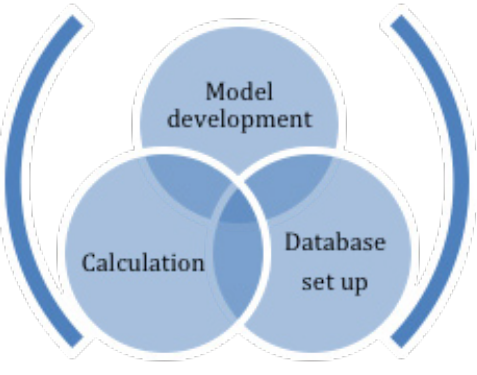

Model

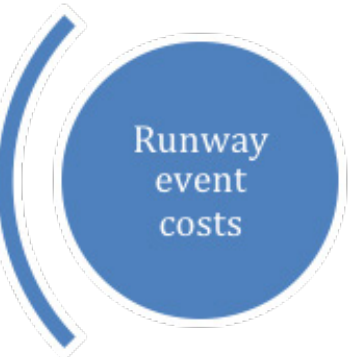

Output

Fig. 2.

Method

Source: Safe-Runway GmbH 


\subsection{The Model}

\subsubsection{Introduction}

Expressing the effects to society of the various runway accidents in costs allows prioritizing of mitigations and policy. This paper identifies costs over four topics:

- Costs of disruption of operation;

- Costs of damage to property or equipment;

- Costs of human injuries or casualties;

- Indirect related accident costs.

\subsection{Costs of Disruption of Operation}

The costs or disruption of operation are related to the duration of a runway or aerodrome closure. When data gathered from the accident does not provide the duration of runway or aerodrome closure it is calculated. Estimating the time of runway closure as a result of a runway related event is done in line with (Wright and van Eekeren, 2016). The main variables into that calculation are the type of aircraft, the type of aerodrome, the availability of auxiliary services, the ability of the aircraft to move and the severity of the accident (level of damage and injuries). The main elements result in opportunity costs, diversion and holding costs and passenger compensation fees, re-bookings etc.

\subsubsection{Aerodrome Operator}

Aerodrome operator costs consist mainly of opportunity costs. The input variables to calculate the aerodrome operator opportunity costs are: Type of aerodrome, duration of runway closure, type of flights to the aerodrome, their distribution, landing fees per category of aircraft, number of passengers affected, passenger fees and traffic density. The costs related to passengers extra lodging, food, parking etc. are not taken into account. A certain number of larger airports with multiple runways have the opportunity to redirect the traffic towards non-favourable runways at the same aerodrome. The extra associated costs (extra delays, environmental impacts, extra operational costs, inefficiency of operation, additional safety impacts, etc.) are assumed to compensate for the reduced costs of diversions as compared to airports with a single runway.

\subsubsection{Type of Aerodrome}

For simplicity are four types of aerodromes / airports / airfields taken. The principle distinction lies in the type of operation.

Hub (used by one or more airlines to concentrate passenger traffic and flight operations at the aerodrome);

Regional (serving traffic with a relatively small or lightly populated area, or not serving the country's major city);

Municipal or Strip (mainly intended for light aircraft operations or local destinations);

Military (could also include joined civilmilitary use).

\subsubsection{Aerodrome Costs}

Opportunity costs calculation is based on the MCTOM, the number of passengers and the associated fees as an input.

Traffic distribution varies per type of airport. A generic distribution is assumed with Hub's emphasis on Wide and Narrow body aircraft; Regional aerodromes a mix between all types and Municipal airports 
emphasis on light aircraft. The traffic density is assumed to be 50 movements per hour for Hub, 25 for Regional and 10 for Municipal aerodromes. The landing fees and passengers fees are derived from averaging 5 airports per category on open source available fees and are simplified to generic figures. It is assumed that for Hubs the average MCTOM is $300000 \mathrm{~kg}$, carried out with 300 passengers; for Regional airports 30 $000 \mathrm{~kg}$ with 30 passengers and for a Municipal / Strip airport $3000 \mathrm{~kg}$ with 3 occupants.

Table 1

Fleet Mix per Type Aerodrome Assumption

\begin{tabular}{|l|l|l|l|}
\hline Fleet Mix \# Movements per Hour & Wide Body & Narrow Body & Small \\
\hline Hub & 15 & 35 & 0 \\
\hline Regional & 3.75 & 17.5 & 3.75 \\
\hline Municipal / Strip & 0 & 3 & 7 \\
\hline
\end{tabular}

Source: Safe-Runway GmbH

Table 2

Fleet Composition and Traffic Mix per Type Aerodrome Assumption

\begin{tabular}{|l|l|l|l|}
\hline \multicolumn{2}{|l|}{ Type Traffic Distribution per Type Aerodrome } & Input & $<\mathbf{5 . 7}$ \\
\hline Fleet Composition & $>\mathbf{4 5 . 3}$ & $\mathbf{5 . 7 - 4 5 . 3}$ & $5 \%$ \\
\hline Hub & $80 \%$ & $15 \%$ & $20 \%$ \\
\hline Regional & $50 \%$ & $30 \%$ & $80 \%$ \\
\hline Municipal & $0 \%$ & $20 \%$ & Local \\
\hline Traffic Mix & ICA & Regional & $0 \%$ \\
\hline Hub & $30 \%$ & $70 \%$ & $15 \%$ \\
\hline Regional & $15 \%$ & $70 \%$ & $70 \%$ \\
\hline Municipal & $0 \%$ & $30 \%$ & \\
\hline
\end{tabular}

Source: Safe-Runway GmbH

Table 3

Airport Charges per Type Aerodrome Assumption

\begin{tabular}{|l|l|l|l|}
\hline Airport Charges & MCTOM/1000k & per pax & Movements \\
\hline Hub & $15.0 €$ & $25.0 €$ & 50 \\
\hline Regional & $12.5 €$ & $20.0 €$ & 25 \\
\hline Municipal & $10.0 €$ & $5.0 €$ & 10 \\
\hline
\end{tabular}

Source: Safe-Runway GmbH 


\subsubsection{Runway and Aerodrome Equipment Damage Costs}

Repair costs to runway, its environment and equipment are not taken into account. Realistic assumptions are precluded due to a serious lack of sufficient data. Even rough estimating the aerodrome repair costs is precluded.

\subsection{Aircraft Operator Costs}

\subsubsection{Type of Aircraft}

Motorized, fixed wing aircraft that require using a runway are included in the aircraft types. Thus helicopters, gliders, ultralights, water planes, etc. are precluded. Specific aircraft type and age is needed for the list price and the current market value. Variations in regulations between EASA, FAA and other major aviation authorities and ICAO preclude a common uniformly differentiation between the various aircraft types. Therefore a more practical approach has been taken to categorize the various aircraft types in two categories based on Maximum Certified Take off Mass (MCTOM) and Maximum Certified Passenger Seating Capacity (MCPSC):

- MCTOM

o Below $5700 \mathrm{~kg}$;

o Between $5700 \mathrm{~kg}$ and $45300 \mathrm{~kg}$;

- Above $45300 \mathrm{~kg}$.

- MSCPSC

o 6 seats and less;

- Between 7 and 11 seats;

- Between 12 and 19 seats;

- Between 20 and 100 seats;

o Above 100 seats.

- Narrow Body;

- Wide Body.

\subsubsection{Diversion Costs and Delay Costs}

When an unexpected runway closure occurs, it is assumed that aircraft will have enough fuel to hold and land at the accident airport for runway closures up to 30 minutes. A runway closure exceeding 30 minutes would normally cause aircraft to divert to a destination or en-route alternate. The diversion costs (EUROCONTROL, 2015) are estimated at $\$ 100000$ for a wide body and $\$ 20000$ for a narrow body CAT and assumed to be $\$ 1000$ for small aircraft. The airborne delay costs for wide and narrow body are assumed to average at $\$ 81$ per minute (PRU, 2004).

It is assumed that with runway closures, aircraft operators will have the possibility to reschedule their operations already in the dispatch phase after a certain time frame. That poses a limit to the maximum diversion costs. It is assumed that dispatch re-scheduling is possible after 12 hours for CAT wide body operations, 4 hours for CAT narrow body and 1 hour for the small aircraft category. The extra associated costs with rescheduling, redirection of manpower and crew rotations are not taken into account. Therefore are the diversion and delay cost conservative.

\subsubsection{Passenger Compensation Fees}

EU legislation 261/2004 (EC, 2004) provides passengers the right to claim delay compensation. This is valid for flights originated within the EU (including Switzerland, Norway and Island) or arriving with an airline thereof. Depending on the travel distance and number of hours delay, the delay compensation varies between $€ 250,400$ and 600 . No compensation is eligible in "extraordinary" circumstances. 
Calculation of the delay compensation is simplified based on a standardized traffic distribution (flights with less than $1500 \mathrm{~km}$; between $1500 \mathrm{~km}$ and $3500 \mathrm{~km}$ and more than $3500 \mathrm{~km}$ ) per type of the aerodrome. The flight distances are assumed to be in line with the various types of aircraft (wide body, narrow body or small aircraft). That results in an assumed traffic distribution as shown and in hourly passenger delay compensation.

This is only applicable for the EU region and is not taken into account for all the other worldwide regions.

Table 4

Passenger Compensation Assumption

\begin{tabular}{|l|l|l|l|}
\hline Passenger Compensation Fees & & & \\
\hline Delay Departure & 2 & 3 & 4 \\
\hline Flight Distance & $<1500$ & $1500-3500$ & $>3500$ \\
\hline EU & $250 €$ & $400 €$ & $400 €$ \\
\hline Outside EU & $250 €$ & $400 €$ & $600 €$ \\
\hline Checked in luggage & $1220 €$ & $1220 €$ & $1220 €$ \\
\hline
\end{tabular}

Source: Safe-Runway GmbH

\subsubsection{Lost Luggage Compensation}

Passengers are eligible for compensation to a maximum of $€ 1220$. It is assumed that this is only applicable for those runway occurrences where the aircraft is destroyed. It will than only affect those passengers in that specific aircraft and also only in Europe. The theoretically maximum occurs with a fatal accident of an Airbus 380 with 550 passengers. The maximum lost luggage compensation is thus $€ 670$ thousand. This is compared to the other costs involved negligible. Furthermore is the likelihood remote (only EU, destroyed, questionable if the maximum amount will be applicable for all, and large wide body). Therefore is lost luggage compensation not taken into account in the model.

\subsubsection{Costs of Damage to Aircraft}

The classification of the severity of the runway safety occurrence is taken either from the accident description or by analysis of the supporting material. The level of aircraft damage level is referenced to (ASTER 2001), which differentiates between $0 \%, 15 \%, 50 \%$, $80 \%$ and $100 \%$ to the various categories. If the level of damage is unknown, a moderate damage level is assumed.

\section{Table 5}

Aircraft Damage Relation Assumption

\begin{tabular}{|l|l|}
\hline Description & Level of Damage \\
\hline None & $0 \%$ \\
\hline Minor & $20 \%$ \\
\hline Moderate & $50 \%$ \\
\hline Substantial & $80 \%$ \\
\hline Destroyed & $100 \%$ \\
\hline Unknown & $50 \%$ \\
\hline
\end{tabular}

Source: (ASTER, 2001). 
Calculation of the aircraft damage costs depends on the level of damage, aircraft type, original, list price and the current market value (CMV). The current market value is calculated by the depreciation rate as supplied by (ASTER, 2001) from the original list price. The list new price of aircraft is derived from open sources. If the new price data are not available a hypothetical new price is taken: For aircraft with a MCTOM
$<5700 \mathrm{~kg}$ is this assumed at $\$ 250000$; between $5700 \mathrm{~kg}$ and $45300 \mathrm{~kg}$, at $\$ 5$ million and above $45300 \mathrm{~kg}$ at $\$ 50$ million. If the age of the accident aircraft is unknown, it is assumed to be 6 years old.

The CMV for older aircraft is considered not really representative due to the low original list price and the current maintenance costs. Therefore is as a bottom $30 \%$ taken.

Table 6

Aircraft Depreciation Assumption

\begin{tabular}{|l|l|l|l|l|l|}
\hline Age & CMV & Age & CMV & Age & CMV \\
\hline 0 & $100 \%$ & 10 & $52 \%$ & 20 & $37 \%$ \\
\hline 1 & $92 \%$ & 11 & $49 \%$ & 21 & $36 \%$ \\
\hline 2 & $86 \%$ & 12 & $46 \%$ & 22 & $36 \%$ \\
\hline 3 & $81 \%$ & 13 & $44 \%$ & 23 & $36 \%$ \\
\hline 4 & $76 \%$ & 14 & $41 \%$ & 24 & $35 \%$ \\
\hline 5 & $71 \%$ & 15 & $40 \%$ & 25 & $35 \%$ \\
\hline 6 & $66 \%$ & 16 & $39 \%$ & 26 & $35 \%$ \\
\hline 7 & $62 \%$ & 17 & $38 \%$ & 27 & $33 \%$ \\
\hline 8 & $58 \%$ & 18 & $38 \%$ & 28 & $33 \%$ \\
\hline 9 & $54 \%$ & 19 & $36 \%$ & 29 & $33 \%$ \\
\hline
\end{tabular}

Source: (ASTER, 2001).

\subsection{Human Injuries or Casualties Costs}

\subsubsection{Abbreviated Injury Score}

The Abbreviated Injury Score (AIS) is considered useful and a representative tool for classifying and identifying the costs of human injury also in aviation accidents (van Eekeren, 2016). The AIS list compromises Minor, Moderate, Serious, Severe, Critical and Fatal injuries; corresponding with
AIS levels 1 to 6 with predefined medical relations to the level of injury. The number of occupants per accident aircraft is gathered and included in the data enabling calculating the risk per occupant. The costs per accident are dependent on the number per AIS category and their associated costs. The costs per AIS category are based on reports by (ASTER, 2001) and (GRA, 2004). Corrected for inflation results in the amounts as listed in figure 10 . 
Table 7

Human Injury Costs per AIS Assumption

\begin{tabular}{|l|l|l|}
\hline AIS Code & Description & Input \\
\hline AIS 1 & Minor & $9424 €$ \\
\hline AIS 2 & Moderate & $49901 €$ \\
\hline AIS 3 & Serious & $173846 €$ \\
\hline AIS 4 & Severe & $631032 €$ \\
\hline AIS 5 & Critical & $2322281 €$ \\
\hline AIS 6 & Fatal & $2803521 €$ \\
\hline
\end{tabular}

Source: Safe-Runway GmbH

\subsubsection{Disruption of Operation due to Injuries and Fatalities}

It is assumed that the appropriate authority will require a more stringent investigation when human casualties are involved in the accident. The same applies with larger numbers of severe injuries. Thus a relation between numbers of the various AIS scores exists. It is assumed that a formal investigation (e.g. police) or treatment at the spot, it would take 3 hours from the time of occurrence to release of the runway traffic for AIS 6 and 5. For (severe) injuries it is assumed that this would take a minimum of one hour. For moderate injuries, requiring medical assistance a closure of 15 minutes is assumed to be the minimum.
Multiple fatalities or injuries resulting from a runway accident are likely to require more operational restrictions as required by investigations. E.g. removing 50 human remains from an accident scene takes more time than removing 50 injured passengers by ambulances or by foot. It is assumed that per AIS 6 or 5 an average of 60 minutes is needed and for 3 and 4 would be 30 minutes.

Secondary and social effects, such as non- or lost production due to sick leave, insurance premium differences etc. are not taken into account. When the accident report provided insufficient detail (e.g. "some persons were injured"), it is assumed that these injuries were AIS 2. The costs associated with human injuries and fatalities are therefore also conservative.

Table 8

Runway Closure Assumption per AIS Category

\begin{tabular}{|l|l|l|l|l|}
\hline Human & & & & \\
\hline Runway Closure Time Related to AIS in Minutes & AIS & min\# & Time per Person & Min RWY Closure \\
\hline Note: Able Body & 1 & 5 & 5 & 15 \\
\hline Note: Medical Assistance & 2 & 2 & 10 & 30 \\
\hline Note: Accident/Severe Incident Investigation & 3 & 2 & 30 & 90 \\
\hline Note: Accident/Severe Incident Investigation & 4 & 2 & 30 & 90 \\
\hline Note: Police Investigation & 5 & 1 & 60 & 180 \\
\hline Note: Police Investigation & 6 & 1 & 60 & 180 \\
\hline
\end{tabular}

Source: Safe-Runway GmbH 


\subsection{Indirect Safety Costs}

Indirect Safety Costs (ISC) includes investigation costs, search and rescue, recovery, legal, third party costs, loss of investment income, loss of reputation, increase of insurance premium, and loss of business due to PR, etc. Although these costs will also effect the costs for aerodrome operators, aircraft operators and society, they are taken as a separate entity. The ISC are listed as a separate item, but will have to be paid by one or more of the runway occurrence associated parties. These are most likely the aircraft operator, the aerodrome operator, the victims and or the government and or their insurance companies. How the distribution of the ISC amongst those is, has not been researched. The indicated costs per operator are therefore conservative

Various methods are available for calculating these costs, some to a great extent and detail. (Cavka and Cokorilo, 2012) identified a method to relate the indirect safety costs (ISC) with the Direct Safety Costs (DSC).

Depending on the severity of the accident is a certain percentage added to the DSC.

For simplicity is the median taken to calculate the ISC from the DSC. The input variables are the severity of the event, the accident costs (excluding the costs of diversions, fees and opportunity costs) and the median ISC.

Table 9

Relation ISC with DSC Assumption

\begin{tabular}{|l|l|l|l|l|l|}
\hline Classification & Minor & Moderate & Major & Disaster & Catastrophic \\
\hline ISC as a Function of DSC & $5-15 \%$ & $25-40 \%$ & $50-70 \%$ & $85-110 \%$ & $90-140 \%$ \\
\hline Median ISC as a Function of DSC & $10 \%$ DSC & $32.5 \%$ DSC & $60 \%$ DSC & $97.5 \%$ DSC & $115 \%$ DSC \\
\hline
\end{tabular}

Source: (Cavka and Cokorilo, 2012)

\subsection{Purchasing Power}

All calculations and assumptions are based on the US cost of living and expressed in US dollars. A purchasing power correction is needed to provide a more realistic indication. A number of system are available, the light- hearted guide to compare currencies, introduced by the Economist in 1986 and known as the Big Mac index is taken.

It provides a quick general and accepted correction method for regional purchasing power. 


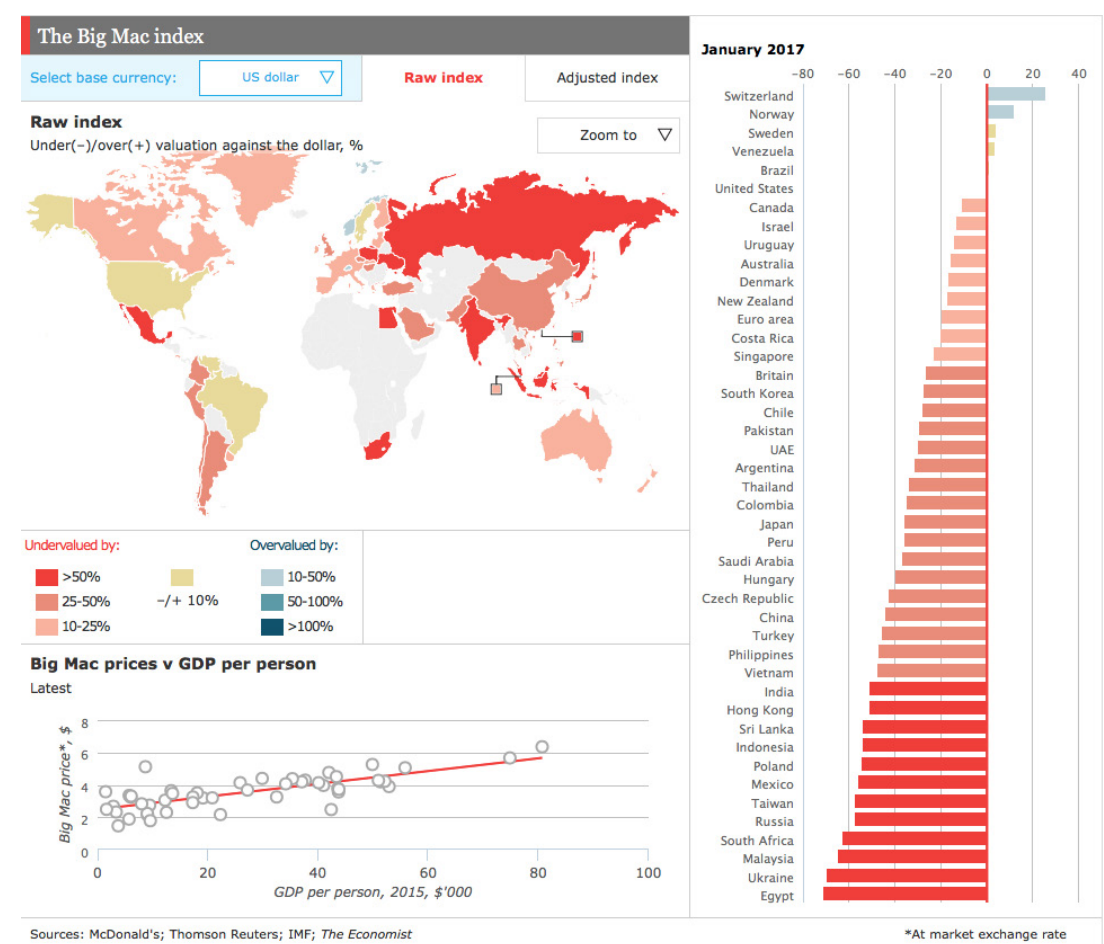

Fig. 3.

Regional Purchasing Power

Source: Economist (2017)

\section{Results}

The 2016 total costs as a result of runway related accidents and incidents is estimated at 5.8 Billion $\$$. Correcting these costs for the various regional effects of purchasing power provides a total cost of 4,2 Billion $\$$.

As a result from all these variables are the aerodrome opportunity costs estimated per runway accident / incident and totalled per year 2016. These are corrected for regional purchasing power estimated at 160 Million Dollars. The aerodrome costs are conservative due to the lack of insight in the repair costs.
The aircraft operator's costs include the extra operational costs (delays and diversions), passenger compensations, aircraft damage and additional costs. The latter are listed under the Indirect Safety Costs (ISC) (see chapter 2.5). The worldwide 2016 aircraft operator's costs related to runway occurrences (excluding the ISC) are estimated at 2,4 Billion Dollar (purchasing power corrected).

In 2016140 people lost their lives and 264 were injured during runway related accidents. The 2016 total costs associated are estimated at 308 Million \$ (purchasing power corrected). 
The ISC for 2016 are estimated at 1.3Billion \$ (Purchasing power corrected). Parts of these costs are likely to be covered by the aircraft operators, aerodrome operators and governments.

\section{Discussion}

\subsection{Quality Questions}

The first question is if the 2016 database is representative. The database compromises 643 runway related accidents and incidents of motorized aircraft required to use a runway during the period 01-01-2016 to 31-12-2016. If that period is representative for the allprevious years has not been researched, neither if the $600+$ occurrences are enough to draw solid conclusions. (Van Es, 2010) concluded that there was no significant drop in average number of runway occurrences over the period 2011-2014 as compared to the 1995-2008 figures. The Flight Safety Foundation concluded that 2016 was the second safest year in aviation history. Therefore it seems appropriate to assume that the 2016 figures are conservative as compared to the past years.

The second question is if the chosen distribution of the costs is useful. The concept of "who pays?" sounds appealing, but has also limits. The ISC are listed as a separate item, but will have to be paid by one or more of the runway occurrence associated parties. These are most likely the aircraft operator, the aerodrome operator, the victims and or the government and or their insurance companies. How the distribution of the ISC amongst those is, has not been researched. The indicated costs per operator are therefore conservative.
The third question is if the used data are representative. An open source database covering all worldwide runway related accidents has not been found. Free newsgathering and social media opened the possibility to gather quick and accessible information. The reliability of these sources is not officially guaranteed, thus the correctness might be questioned. Nowadays widespread use of social media, cell phones and Internet make it possible that almost immediately accidents are shared (e.g. cell phones of passengers). Although fake posts cannot be excluded, is it more likely that data on accidents / severe incidents are incomplete rather than incorrect. Areas of concern are those regions where full freedom of the press is not available and / or certain restriction on social media is experienced. One region in particular was noticed with no reports at all: China. That results in under reporting via open sources. Therefore the total worldwide costs are conservative.

The fourth question is if the costs as indicated in this paper are reasonably complete. As indicated could a number of costs not be retrieved nor estimated (e.g. damage to aerodrome equipment, runways, secondary or social effects, loss of production days, redirection of manpower handling the occurrence, etc.) The ISC do not cover all of these costs. Therefore are the total worldwide costs conservative.

The final question is if the method used for estimating the costs can be regarded as adequate. In the ideal world, aircraft operators, aerodrome operators, insurance companies, aviation authorities and governments would share openly the data and costs associated with runway occurrences. This is not the 
case. Therefore is a method of estimating the associated costs the only method to gain some insight. Since a limited number of official accidents of incident investigations are undertaken and published, is it impossible to get all data from official sources. Additionally reports are often published well after an event has taken place, making direct analysis of known runway events impossible. Even though the shortcomings of the method, resulting in underestimating of the factual costs, can it be concluded that it provides a general useful indication of the costs involved in unexpected runway closures due to accidents and incidents.

\subsection{Research}

Further research is recommended to further improve the accuracy of the cost estimations. Research should compromise, but is not limited to: Improve the data gathering, the costs associated with aerodrome damage; get insight in the cost distribution within the ISC's, validation and develop a user friendly model as a tool in the SMS decision making process. Secondly is further research advisable to derive to solid conclusions on how to cost effectively mitigate runway safety events; including addressing the severity of an event.

\subsection{Conclusion}

The used method of getting grip on the cost related to runway safety events provides a reasonable insight that can be used by relevant authorities in their rule making and or decision making processes. Aircraft and aerodrome operators might also find it useful to gain insight in the costs associated with runway events. Those help in choosing mitigations or accept the risk as it is within their safety management systems.
The results show that the costs related to runway occurrences are high. The model allows more detailed and custom made cost analyses, which enables users to use it as a management decision tool for cost effective safety mitigations.

\section{References}

ASTER. 2001. Aviation Safety targets for effective regulation - consolidated final report. National Aerospace Laboratory NLR, Amsterdam, Netherlands. 89 p.

Cavka, I.; Cokorilo, O. 2012. Cost-benefit assessment of aircraft safety, International Journal for Traffic and Transport Engineering 2(4): 359-371.

EUROCONTROL. 2015. Standard Inputs for EUROCONTROL Cost-Benefit Analyses. Edition 7.0. 108 p.

EUROCONTROL. 2017. Available from internet: <http:// www.skybrary.aero/index.php/Runway_Excursion $>$.

EAPPRE. 2013. European Action Plan for the Prevention of Runway Excursions edition 1.0 (2013). EUROCONTROL, Brussels, Belgium. 96 p.

EAPPRI. 2012. European Action Plan for the Prevention of Runway Incursions edition 2.0 (2012). EUROCONTROL, Brussels, Belgium. 104 p.

EASA. 2017. Annual safety review 2017. European Aviation Safety Agency. Cologne, Germany. 117 p.

EC. 2004. (EC) No 261/2004. Available from Internet: <http://data.europa.eu/eli/reg/2004/261/oj>

GRA. 2004. Economic values for FAA investment and regulatory decisions, a guide. Contract DFTA 01-02C00200. FAA, Washington, USA. 135 p.

PRU. 2004. Evaluating the true cost to airlines of one minute of airborne or ground delay. Eurocontrol, Brussels, Belgium. 260 p. 
Van Eekeren, J. 2016. Future sky safety Europe: Cost benefit analysis of runway occurrences. Available from Internet: <https://www.futuresky-safety.eu/wpcontent/uploads/2017/03/0803-FSS-Workshop_04 Van-eekeren_SAfe-Runway.pdf $>$, accessed at 01.03.2016.

Van Es, G.W.H. 2010. A study of runway excursions from a European perspective. NLR-CR-2010-259.

Wright, S.; van Eekeren, J. 2016. Estimating the duration of runway closures due to unexpected runway safety events from historical data, The aeronautical journal aerospace (in print). 